\title{
LA PEQUEÑA EDAD DEL HIELO EN LA REGIÓN CENTRAL DE LA REPÚBLICA ARGENTINA
}

\author{
POR \\ MARCELA CIOCCALE
}

\section{Introducción}

Desde el final de la última glaciación el clima de la tierra ha sido más o menos constante, la temperatura promedio de la superficie terrestre flutuó alrededor de un grado o dos respecto a los niveles actuales. Sin embargo, sobrepuesto a esta relativa uniformidad, se han sucedido una serie de variaciones climáticas menores que han tenido impacto sobre diversos aspectos: geología, biología y fundamentalmente sobre el hombre (Murck et al., 1995). Dentro de las fluctuaciones recientes la «Pequeña Edad del Hielo» (PEH) constituye el evento global frío más importante en la evolución del clima, en el curso de los dos últimos milenios (Blij y Muller, 1993). Comenzó a finales de la Edad Media y se prolongó hasta principios del siglo XIX. Las temperaturas descendieron alrededor de $0,6^{\circ} \mathrm{C}$ por debajo de la norma de referencia (1900) (Riccardi, 1995).

Numerosos investigadores de las ciencias de la tierra han detectado el cambio climático correspondiente a la $\mathrm{PEH}$, en distintos ambientes y por medio de diferentes criterios metodológicos (Mercer, 1970; Heusser, 1961; Politis, 1984; Rebassa et al., 1985; Latrubesse y Ramonell, 1990, Iriondo y Kröhling, 1995, etc.). También los historiadores han realizado importantes aportes sobre esta temática, a través del estudio de registros

Marcela Cioccale: Facultad de Ciencias. Univ. Nacional de Córdoba (Argentina). 
históricos y cartográficos, reconstruyendo las condiciones climáticas reinantes durante la época colonial (Herrera Dussel, 1992; Prieto y Herrera, 1992, y Prieto Jorba, 1991).

En la República Argentina la PEH se manifestó con avance de los glaciares en la cordillera de Los Andes y aridez en las regiones bajas (Politis, 1984; Rabassa et al., 1984; Iriondo y Kröhling, 1995). El efecto de este suceso se reflejó en la llanura repitiendo a menor escala los patrones del Último Máximo Glacial (Iriondo, 1994).

El presente trabajo tiene como objetivo examinar varias líneas de evidencias que concurran a explicar las condiciones ambientales de la $\mathrm{PEH}$ en la región central de la República Argentina entre los siglos Xv y XIX*.

\section{Aspectos metodológicos}

Se llevó a cabo una investigación de los cambios climáticos ocurridos durante los últimos ochocientos años en la región central de Argentina, basada en el análisisis de imágenes de satélite y fotografías aéreas, evidencias de campo, antecedentes históricos y registros meteorológicos. Además, se analizaron los trabajos previos de geólogos, arqueólogos e historiadores que proporcionaron la base para la elaboración del modelo propuesto. Se avanzó en dos corrientes de investigación, por un lado se elaboró un modelo geográfico y por otro se desarrolló una secuencia temporal de las diferentes situaciones climáticas.

El primer caso consistió en la escenificación de un momento de máxima aridez durante PEH. Para ello se efectuó un estudio cartográfico comparativo de cada elemento del paisaje, respecto a las condiciones climáticas actuales, complementado por información suministrada por los trabajos previos, correlación estratigráfica regional y reconocimientos geomorfológicos. El modelo temporal se basó fundamentalmente en datos históricos, arqueológicos y glaciológicos que permitieron realizar un análisis secuencial de toda la información disponible, confrontándola con el clima presente.

La región se ubica en el sector central de la República Argentina (en-

* He de expresar mi agradecimiento al Dr. Claudio Carignano por su apoyo permanente y la lectura crítica del manuscrito.

$$
-250-
$$




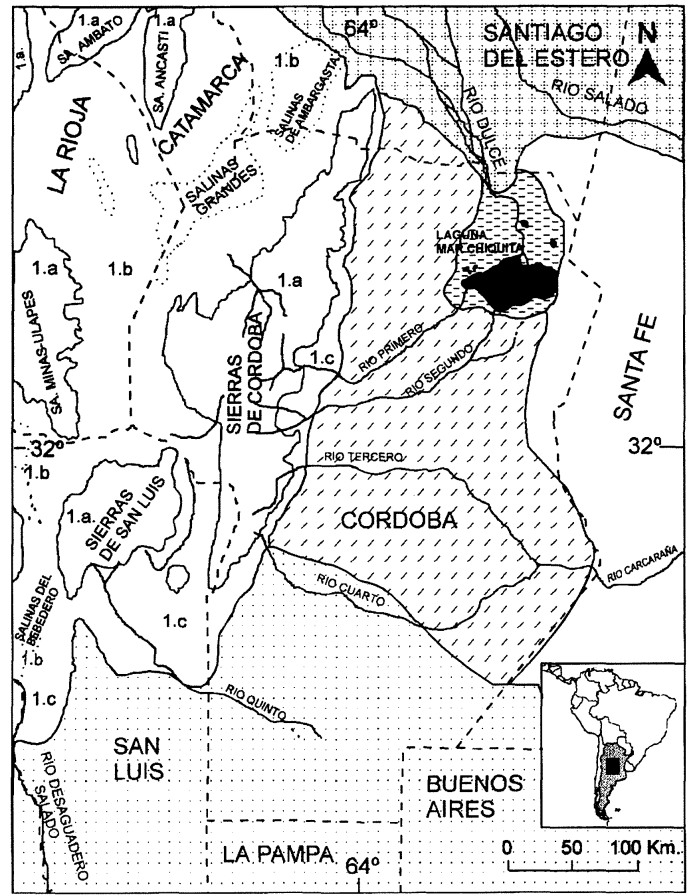

\section{Referencias}

1. Sierras Pampeanas

1.a. Sierras

1.b. Bolsones

1.c Piedemonte

\section{Llanura Pampeana}

Llanura eólica arenosa

Llanura eólica loéssica

LIanura aluvio-eólica loéssica

Llanura lacustre

Llanura aluvial de los ríos Dulce y Salado

-. - Límite interprovincial

-. Lagunas

Fig. 1.-Región Central de la República Argentina.

tre los $28^{\circ} \mathrm{S}-36^{\circ} \mathrm{S}$ y $\left.\operatorname{los} 61^{\circ} \mathrm{W}-67^{\circ} \mathrm{W}\right)$. Comprende dos grandes regiones geomorfológicas: Sierras Pampenas y Llanura Pampeana (fig. 1).

\section{Sierras Pampeanas}

El sector Oeste de la región es una zona montañosa que abarca los cordones orientales del Sistema de Sierras Pampeanas. Se trata de macizos cristalinos antiguos que han sufrido sucesivos eventos erosivos, conformando un paisaje caracterizado por restos de superficies de erosión, que posteriormente fueron basculadas y elevadas tectónicamente durante los movimientos andinos (Carignano, 1997).

Esta unidad puede dividirse en tres grupos principales: sierras, bolsones intermontanos y piedemonte.

$$
-251-
$$


a) Sierras. Están constituidas por los cordones de las Sierras de Córdoba (500-2.790 msnm), San Luis (500-2.150 msnm), Ancasti-Ambato (500-1.624 msnm) y Chepes-Ulapes (500-1.700 msnm). Todas estas sierras presentan un flanco occidental abrupto, correspondiente a grandes escarpes de falla y una vertiente oriental extendida donde se suceden las antiguas superficies de erosión a veces cubiertas por sedimentos terciarios y cuaternarios.

El sistema serrano está incluido dentro de la faja templada, presenta precipitaciones que aumentan con la altura desde 500 a $900 \mathrm{~mm}$. Las temperaturas medias anuales son inferiores que en la llanura, fluctúan entre $\operatorname{los} 10^{\circ} \mathrm{C}$ y $16^{\circ} \mathrm{C}$. Por encima de los $2.000 \mathrm{msnm}$, las bajas temperaturas invernales provocan intensas nevadas.

b) Bolsones intermontanos. Los bolsones intermontanos son cubetas estructurales relativamente llanas, rellenas por sedimentos, que por lo general conforman sistemas endorreicos (o bolsones propiamente dichos). En algunos casos estas depresiones están conectadas con sistemas hídricos que reciben sus excedentes (Iriondo y Ramonell, 1993).

Los fondos de los bolsones endorreicos están ocpados por salinas ubicadas altitudinalmente alrededor de los $200 \mathrm{msnm}$. Los principales salares son: Las Salinas Grandes $\left(4.700 \mathrm{~km}^{2}\right)$, Salinas de Ambargasta $\left(4.200 \mathrm{~km}^{2}\right)$, San Bernardo $\left(7,2 \mathrm{~km}^{2}\right)$, La Antigua $\left(410 \mathrm{~km}^{2}\right)$. El conjunto constituye uno de los sistemas hipersalinos más grandes del mundo (Dargám, 1995). Estas depresiones se caracterizan por tener climas áridos con precipitaciones menores a los $400 \mathrm{~mm} /$ año concentradas en la estación estival, amplia amplitud térmica y alto déficit de agua (Capitanelli, 1976).

Al Suroeste, se encuentra el bolsón exorreico de las Salinas del Bebedero (380 $\mathrm{msnm}$ ), perteneciente a la cuenca Desaguadero-Salado $\left(248.000 \mathrm{~km}^{2}\right)$. Este sistema hídrico, durante el presente siglo, ha perdido progresivamente su conexión con el Atlántico. En la actualidad, su nivel de base lo encuentra en la laguna Urre Luquen, ubicada al Oeste de la provincia de La Pampa (Véscovo, 1981).

c) Piedemonte oriental de las Sierras de Córdoba y Piedemonte del Sur de las Sierras de San Luis. El ambiente pedemontano se extiende desde los últimos afloramientos orientales de las Sierras de Córdoba y Sur de San Luis hasta alrededor de los $400 \mathrm{msnm}$ donde se observa un cambio de pendiente que acompaña la variación de morfología. 
El piedemonte oriental de las Sierras de Córdoba es una estrecha franja de 15 a $20 \mathrm{~km}$ de ancho, que está integrada por una serie de abanicos aluviales coalescentes, que han sido cortados y cubiertos sucesivamente. Los sedimentos son de origen fluvial, haciéndose progresivamente más finos hacia el Este, donde en forma gradual se confunden con arenas fluvio-eólicas y materiales de tipo loéssico (Carignano, 1997).

El piedemonte Sur de las Sierras de San Luis muestra un relieve de mesillas alargadas de cumbre piana, producto del desarrollo de dos niveles sucesivos de pedimentación (Iriondo y Ramonell, 1993), dominan los sedimentos loéssicos y loessoides que hacia el Sur se interdigitan con los sedimentos arenosos de la Llanura Eólica.

Las condiciones climáticas del piedemonte están directamente afectadas por la altura; esta región recibe precipitaciones mayores que el promedio de la llanura aledaña y las temperaturas medias anuales son entre $1^{\circ}$ y $3^{\circ} \mathrm{C}$ menores que su equivalente latitudinal en la llanura.

\section{La Llanura Pampeana}

La Llanura Pampeana es una amplia planicie de $600.000 \mathrm{~km}^{2}$. Se trata de una extensa área muy uniforme, constituida por sedimentos finos (limos y arenas) depositados por procesos eólicos, fluviales y lagunares. Altitudinalmente se localiza entre 80 y $400 \mathrm{msnm}$ en el contacto con el piedemonte serrano.

Esta gran cubierta sedimentaria conforma el «Sistema Eólico Pampeano», el cual está compuesto por el Mar de Arena Pampeano y la Faja Periférica de Loess, al Sur y Norte respectivamente (Iriondo y Kröhling, 1995).

La llanura presenta clima templado, las temperaturas medias anuales aumentan hacia el Norte fluctuando entre los $16^{\circ} \mathrm{C}$ y $18^{\circ} \mathrm{C}$. Los promedios de las precipitaciones decrecen hacia el Oeste de 900 a 500 $\mathrm{mm} / \mathrm{año.}$

La región de estudio abarca el sector central y occidental del Sistema Eólico Pampeano. De acuerdo al origen, formas y procesos predominantes se distinguen cinco sub-unidades (según la clasificación de llanuras propuesta por Iriondo (1987):

a) Llanura eólica arenosa. Está ubicada al Sur de la región y corresponde al Mar de Arena Pampeano, se extiende por debajo del pa- 
ralelo $34^{\circ}$, el cual es considerado aproximadamente el límite externo de la movilización de arenas durante los eventos secos (Iriondo y Kröhling, 1995). Se trata de un sector de la llanura pampena donde prevalecieron los procesos eólicos que generaron cubetas de deflación, campos de dunas y mantos de arenas (Carignano, 1997). A estas formas se le suman valles muy amplios correspondientes a paleocauces del Río Quinto formados durante eventos húmedos anteriores (Iriondo, 1986).

b) Llanura eólica loéssica. Abarca el sector Este de la región y está incluida dentro de la Faja Periférica de Loess, es una planicie muy homogénea, con pendientes muy bajas cubierta por sedimentos loéssicos de espesor variable (7-10 m) Iriondo y Kröhling (1995). Su escaso relieve favorece la formación de lagunas muy someras y pantanos, que desaparecen en épocas de sequía.

c) Llanura aluvio-eólica loéssica. Está ubicada en el centro de la región y corresponde a la parte occidental de la Faja Periférica de Loess (Iriondo y Kröhling, 1995). Es una extensa continuación del piedemonte de las Sierras de Córdoba de $180 \mathrm{~km}$ de largo por $300 \mathrm{~km}$ de ancho (Iriondo, 1987). La pendiente general es hacia el Este, sus alturas mayores están en el contacto con el piedemonte ( $400 \mathrm{msnm}$ ) y las menores (80 msnm) limitan con la llanura eólica-loéssica. Esta planicie ha sido construida por el trabajo conjunto de los ríos y el viento. Se trata de la coalescencia de los abanicos aluviales de los ríos que tienen sus nacientes en las sierras del Oeste: Primero, Segundo, Tercero y Cuarto (Iriondo, 1986). La unidad está dominada por morfología fluvial (paleocauces, terrazas, amplias planicies de inundación abandonadas, etc.) con interfluvios ocupados por sedimentos loéssicos.

d) Llanura Lacustre (Depresión de la Laguna Mar Chiquita). Se extiende al noroeste de la región. Su origen está vinculado a condiciones climáticas y estructurales. El borde oriental está definido por la falla regional Tostado-Selva, que separa esta unidad de la Llanura eólica loéssica. Al Norte se comunica con las partes distales de los abanicos aluviales de los Ríos Dulce y Salado, y al Sur y Este con la Llanura Aluvio-eólica. Se trata de una amplia planicie comprendida en la isohipsa de $100 \mathrm{msnm}$, con una pendiente muy baja del orden de los 1:100 (Capitanelli, 1976). Está constituida por sedimentos finos y muy finos con estratificación laminar. Lagunas someras, pantanos y salares son las formas dominantes del paisaje.

La parte más baja está ocupada por la Laguna Mar Chiquita (70

$$
-254-
$$


msnm), este extenso cuerpo de agua es el más grande del país. Se caracteriza por tener un nivel muy fluctuante, como un área inundada de $2.000 \mathrm{~km}^{2}$ de promedio que a partir de la gran crecida de los años setenta alcanzó una superficie mayor a $5.000 \mathrm{~km}^{2}$.

e) Llanura Aluvial de los Ríos Dulce y Salado. Corresponde al extremo noreste de la región y toma un pequeño sector del Sur de la Llanura Chaqueña. La unidad está formada por la coalescencia de los «Megabanicos» de los ríos Dulce y Salado al Oeste y Este respectivamente (Iriondo, 1987; Iriondo, 1992). El primero nace en los Nevados del Aconquija, y drena una superficie de $34.620 \mathrm{~km}^{2}$, el segundo tiene sus cabeceras en los nevados orientales de la Puna, y abarca una superficie de $247.000 \mathrm{~km}^{2}$. Los sedimentos que componen la llanura provienen del depósito de materiales medianos a finos transportado por los ríos mencionados. Se trata de un sistema de derrame distributario conformado por cauces abandonados, lóbulos de derrame, áreas de bañados, llanuras aluviales, etc. (Iriondo, 1987). Ellos constituyen una planicie de muy bajo relieve que favorece la movilidad de los cauces. En tiempos históricos ambos cursos han sufrido cambios y bifurcaciones que han generado desplazamiento de las poblaciones que se emplazaban a sus orillas.

\section{Reconstrucción del escenario durante la Pequeña Edad del Hielo en la región central de Argentina}

La reconstrucción del escenario pone de manifiesto las condiciones ambientales reinantes durante el pulso del máximo enfriamiento de la $\mathrm{PEH}$ (finales del siglo XVIII) y los procesos geomorfológicos desencadenados como respuesta a un evento climático global de esta naturaleza (fig. 2).

En términos generales la región central de Argentina durante este lapso experimentó un sensible deterioro climático, el clima fue más árido y frío que el actual (Politis, 1984; Rabassa et al., 1984; Iriondo y Kröhling, 1995; Iriondo y García, 1996) y se intensificaron las oscilaciones climáticas con una sucesión de eventos extremos: Sequías-inundaciones (Prieto y Jorba, 1991). En base a la información reunida, análisis de imágenes de satélite y controles de campo se reconstruyó el escenario de las condiciones reinantes durante la PEH (2. ${ }^{\circ}$ pulso): la llanura eólica 


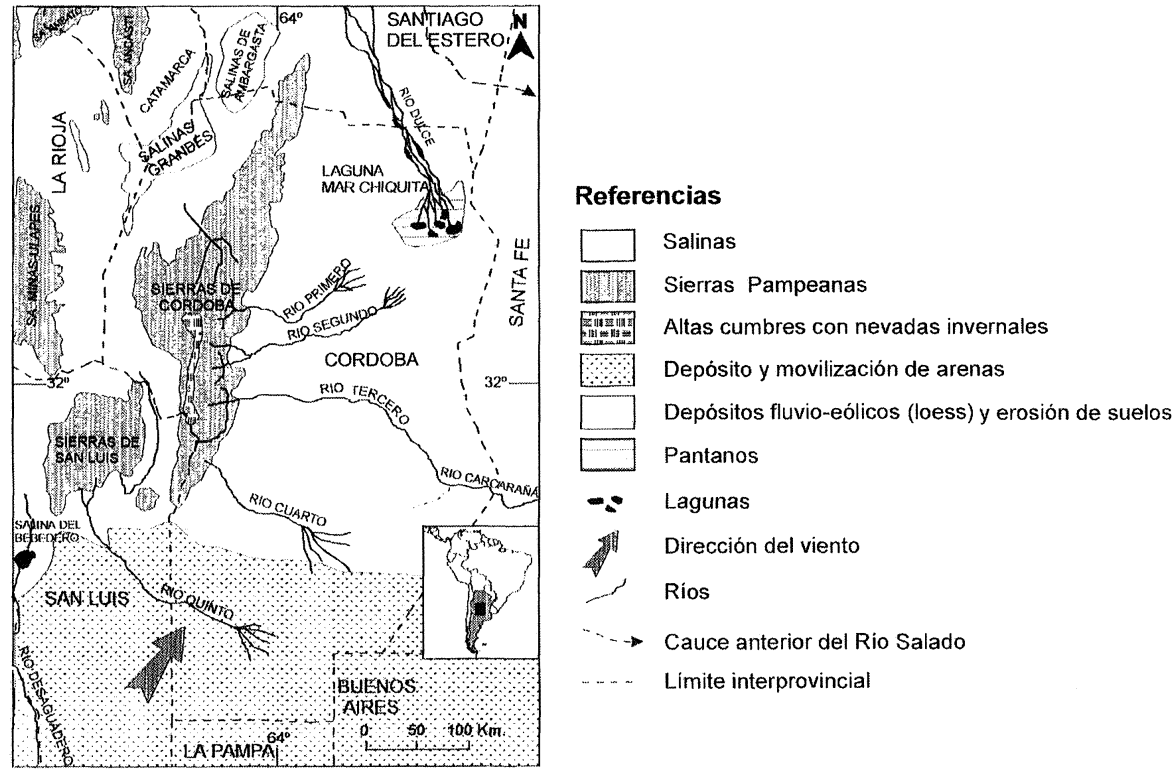

Fig. 2.-Escenario propuesto para la Pequeña Edad del Hielo (XVIII-XIX).

arenosa presentaba intensos procesos eólicos, que quedaron registrados por un delgado manto de arena y las formas desarrolladas bajo condiciones de un clima árido o semiárido, con presencia de fuertes vientos del SO (Iriondo y Kröhling, 1995). Esta dinámica geomorfológica replicó, con menor intensidad, los patrones de anteriores períodos áridos ocurridos durante el Holoceno en la región (Iriondo, 1994; Carignano, 1997).

Numerosos autores han determinado sedimentos correspondientes a la PEH en la llanura eólica arenosa, en casi todos los casos estos materiales arenosos están depositados en discordancia sobre un suelo erosionado (Hypsitermal) o cubriendo suelos o sedimentos lacustres correspondientes al Máximo Medieval (1400-800 AP) (cuadro I).

Fuera del área de estudio hacia el Sur y Sureste (prolongación de la llanura eólica arenosa) se repiten las condiciones enunciadas que han sido descriptas por diversos autores: Politis, 1984, Rebassa et al. (1984), Gentile (1990), Fidalgo y Tonni (1978) y Fidalgo et al. (1991).

El río Quinto, único río que atraviesa la llanura eólica, finalizaba su

$$
-256-
$$




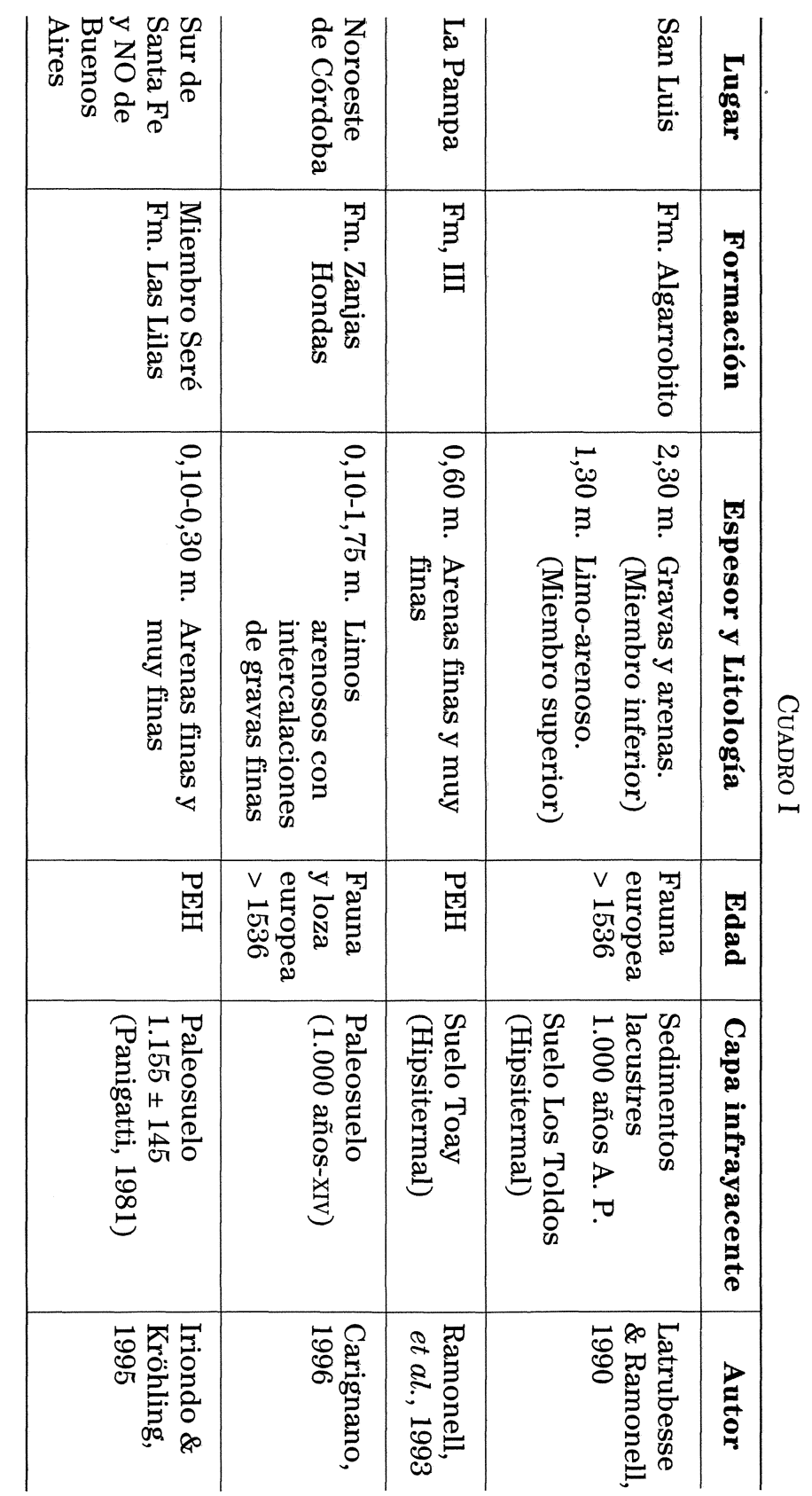

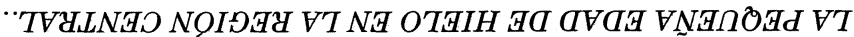


recorrido en una depresión (actuales bañados de la Amarga) ocupada por un pantano o lago, de acuerdo a la intensidad de las lluvias estivales (Furlong, 1946).

Durante este momento reinaron, sobre la llanura aluvio-eólica loéssica, condiciones semiáridas que provocaron en términos generales la retracción de los sistemas fluviales. Los cauces redujeron sensiblemente su caudal infiltrándose en la llanura muchos kilómetros antes que en la actualidad. Los ríos Primero y Segundo se infiltraban antes de llegar a la Laguna Mar Chiquita finalizando su recorrido con el desarrollo de respectivos abanicos aluviales (Mapas de 1760 [32], 1772 [36], Furlong, 1946).

El sistema Río Tercero-Carcarañá mantuvo su actual recorrido, pero mostró un aumento de su contenido salino (Iriondo y Kröhling, 1995). La cartografía jesuítica (Furlong, 1946) y las crónicas describen (Lozano, 1873) al Río Tercero como curso más caudaloso de la región. En todos los registros cartográficos (Furlong, 1946; Torres Revello, 1938; Levillier, 1927) existen representaciones similares, que se corresponden con trazado que lleva en el presente. Este río posee la cuenca más extensa y elevada de las Sierras de Córdoba (>2.000 msnm), tales características hicieron posible mantener su caudal hasta el Río Paraná.

El Río Carcarañá se iniciaba por la unión del Río Tercero y arroyo Saladillo, que durante este lapso aún no estaba unido al Río Cuarto. Este último corría hacia el SE y se infiltraba en una depresión, que en ocasionalmente debido a crecidas estivales extraordinarias era ocupada por una esporádica laguna (Torres Revello, 1938, Furlong, 1946). Concolocorvo (1772) describe los grandes y pequeños ríos de la región, el autor señala el carácter arenoso y fangoso de las lagunas en que éstos ríos terminaban, así como de sus bruscas mutaciones (Levillier, 1927).

La llanura eólica loéssica presentaba condiciones semiáridas, con largos períodos de sequía, que dificultaban la travesía entre Santa Fe y Córdoba. Durante las épocas invernales se esperaba a que lloviera para emprender el viaje (Parras, 1943). La cartografía de la época muestra a esta unidad desprovista de ríos y lagunas de extensión importante (Furlong, 1946).

Los cauces de los ríos Dulce y Salado presentaron durante la PEH, grandes modificaciones. Por medio de la observación de cartografía Jesuítica, se ha podido establecer en el lapso comprendido entre 1609 a 1756 que el río Salado corría aproximadamente como lo hace en la actualidad (Furlong, 1946). Posteriormente, en cartografía de los años

$$
-258-
$$


1760, 1770 y 1772 (Furlong, 1946), el río Salado desembocaba en el sistema de las llamadas Lagunas Saladas de los Porongos (Mar Chiquita). Cabe destacar que en estos mapas se hace expresar referencia del antiguo cauce. Es probable que cambio de curso se haya producido en 1750/52 debido a lluvias extraordinarias que provocaron grandes crecidas de ambos ríos (Herrera-Dussel, 1992). Cartografía de 1774 muestra al Salado (bifurcado) desaguando simultáneamente al Dulce y al Paraná y en 1789 nuevamente se lo encuentra unido al Dulce llegando a las Lagunas de los Porongos (Furlong, 1946).

No se cuenta con registros cartográficos exactos que permitan establecer a partir de cuando el río volvió a desaguar al Paraná, pero en mapas correspondientes a mediados del siglo XIX vuelve a su antiguo cauce y se mantiene así hasta la actualidad. Confirmando esta situación existe numerosa documentación que hace referencias a los cambios de curso del Salado (Herrera-Dussel, 1992).

La gran dinámica que ponen en manifiesto los documentos históricos ha quedado registrada en la llanura aluvial, a través de gran cantidad de paleocauces (área de derrames del Salado) con dirección general OesteEste que hacia el Norte rotan de sudoeste-noreste, completan el paisaje hoyas de deflación alineadas excavadas posteriormente (Iriondo, 1987).

La llanura lacustre (Mar Chiquita) en la segunda mitad del siglo XVIII se presentó como un pantano conformado por lagunas saladas someras interconectadas (mapa [32], Furlong, 1946), bordeadas por arenales y cubetas con fondos salinos (Parras, 1943).

Levillier (1927) identificó para el siglo xviII (a partir de documentos y cartografía) que la llanura lacustre presentaba un sistema lagunar al Norte: Laguna de los Porongos y un pequeño estero al Sur que en tiempos recientes se transformó en la extensa laguna de Mar Chiquita. Kröhling (1993) determinó para este evento una reducción de la laguna y la acumulación de importante cantidad de sales en los sedimentos antes inundados.

Numerosos ríos y arroyos provenientes de las sierras bañaban el piedemonte serrano, el cual presentaba condiciones más benignas que las reinantes en las planicies adyacentes. La mayoría de las corrientes no alcanzaban la llanura, salvo en ocasiones de lluvias estivales extraordinarias. En su tramo final los ríos cambiaron varias veces su curso dejando, como consecuencia, cauces abandonados bien definidos. Como ejemplo de esto, pueden citarse los cambios de curso de los ríos Jesús 
María y Carnero (ubicados al Norte de la ciudad de Córdoba), verificados por comparación entre cartografía de XVIII (Levillier, 1927) y fotografías aéreas e imágenes de satélite.

En los bordes de las sierras este evento está representado por depósitos aluviales. Estos sedimentos, en la actualidad, han sido cortados y constituyen el techo de las barrancas y relleno de cauces. Es frecuente hallar en estas capas arenosas restos de fauna europea, como así también restos de actividad humana (loza, piezas de metal, etc.). En general esta unidad se apoya discordantemente, sepultando diferentes formaciones que han sido sometida a procesos de erosión.

Indudablemente, en las épocas coloniales, el sector pedemontano resultó el más apropiado para el desarrollo de las nuevas poblaciones debido a la cantidad y calidad de sus aguas. En el se ubicaron ciudades y estancias jesuíticas tales como Córdoba, Alta Gracia y Jesús María. Concolorcorvo (1773) en su descripción de los ríos de Córdoba se refiere al Río Primero indicando... «aguas que son claras y no causan fastidio al paladar»... (Levillier, 1927).

Las Sierras Pampeanas, recibían lluvias estivales torrenciales e intensas nevadas invernales, en especial por encima de los $1.500 \mathrm{msnm}$. La cartografía de 1789 identifica las sierras de Córdoba como Montaña nevada de Cordova (Torres Revello, 1938).

Los lagos de las depresiones intermontanas desaparecieron por completo y sus fondos fueron ocupados por los actuales salares (Salinas Grandes, Ambargasta, etc.) (Arignano, 1997). Los grupos humanos que habitaban la región en aquellas épocas sufrieron las consecuencias de un importante deterioro climático, modificando sus comportamientos y sus economías (Laguens y Boninn, 1987). Sin embargo, la depresión ocupada actualmente por la Salina del Bebedero, por ese entonces recibía aguas de deshielo provenientes del Río Desaguadero, lo que permitía la alimentación de la laguna cuya antigua costa fue datada en $350+/-70$ a A.P. (González, 1987). Un plano del territorio de San Luis del año 1794 describe: «... esta Laguna del Bebedero es salada y sus orillas mui pantanosas. Esta circundada por médanos grandes de arena»... (Levene, 1938). Por otra parte Gez (1938) establece que la sustitución del lago por el salar se debió a la interrupción de aporte hídrico del Desaguadero a finales del siglo pasado. Durante la PEH, mientras la Laguna del Bebedero llegaba a la máxima cota, la Laguna Mar Chiquita se convertía en un pantano bordeado por salinas y arenales. Esta conexión Este-Oeste sigue el 
modelo propuesto por Iriondo (1997) donde establece oscilaciones, para las planicies Sudamericanas, entre dos sistemas el Pampeano y el Venezolano.

La fisonomía de la vegetación, en la región de las Sierras de Córdoba, sufrió variaciones respondiendo al deterioro climático. Se han verificado dos cambios notables, por un lado el reemplazo de la Asociación del Chaco Occidental o de Monte, correspondientes a climas más áridos, sobre la Asociación Chaco Oriental, que responde a climas más húmedos (Bonnin et al., 1987) y por otro, el desarrollo de palmares, asociaciones florísticas vinculadas al uso del fuego (Díaz et al., 1987), favorecidas por condiciones de clima más seco, con mayor número de heladas y vientos más intensos que aumentaría la probabilidad de ocurrencia de incendio. En la actualidad el palmar abarca amplios sectores del Norte y Oeste de las Sierras de Córdoba (Lutti et al., 1976), durante la Época Colonial su desarrollo fue notablemente menor (Día et al., 1987).

\section{Conclusiones. Fluctuaciones climáticas durante la Pequeña Edad del Hielo}

La PEH en la región central de Argentina no se manifestó como un evento homogéneo, durante su desarrollo se registraron por lo menos dos pulsaciones frías, separadas por un período intermedio de condiciones más benignas, similares a las actuales o tal vez más húmedos (véase fig. 3).

Primera pulsación. Se extendió desde las primeras décadas del siglo Xv hasta la finalización del siglo XvI. Los datos arqueológicos relevados al NW de la región, permiten establecer a partir del siglo XV una clara decadencia del sistema indígena, que habría estado en crisis antes del contacto con el sistema español (Languens y Bonnin, 1987). El análisis demográfico del período 1500-1700 d. C. muestra una situación de «estrés» poblacional ocasionado por la disminución de la oferta ambiental (Laguens, 1990).

Concidentemente se detecta en la región un cambio en la modalidad de almacenamiento de los elementos inmuebles (alimentos). Estos pueblos construían estructuras subterráneas de tierra cocida, localmente denominados «hornitos», utilizadas como verdaderos silos. En la región se identificaron dos generaciones de dichas estructuras, las más 


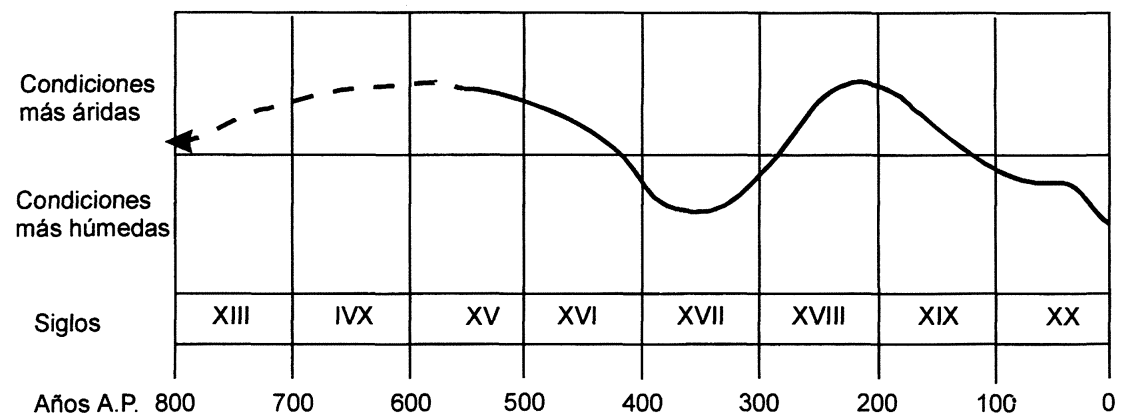

Fig. 3.-Oscilaciones climáticas durante los últimos 800 años.

antiguas presentan menores dimensiones que las más recientes. Este cambio de modalidad ocurrió a mediados del siglo Xvi (1550 d. C., por fechado $\mathrm{C}^{14}$ ). Se interpreta el incremento de volumen de acopio de alimentos, como una manera de minimizar riesgos, tratando de aumentar su capacidad de abastecimiento durante los inviernos (Laguens, 1994).

Los primeros datos históricos de sequías, se refieren a este fenómeno en Santa Fe (fundada en 1573) durante 1592-1593 (Prieto y Jorba, 1991).

La vegetación comienza a sufrir las consecuencias de este deterioro climático, la flora del Chaco Oriental fue reemplazada por la Chaco Occidental correspondiente a climas más áridos (Bonnin et al., 1987).

Este evento puede vincularse con las determinaciones efectuadas por Cardiff (1981) en los Andes Peruanos y coincide con el enfriamiento global conocido como el Mínimo Spörer (mínimo de actividad solar), que se extendió entre 1420-1570 d. C. (Riccardi, 1995).

Período intermedio. Se inició a finales del siglo xv y se prolongó hasta principio del siglo xviII. Durante este período reinó un clima general más benigno, similar al actual, con intercalaciones de algunos años más secos. Bajo estas condiciones se produjo la instalación de la colonia española.

La cartografía correspondiente a este período (Furlong, 1946) muestra a todos los sistemas hídricos (Río Dulce, Salado, Primero, Segundo y Tercero) con caudales suficientes para llegar a sus respectivos niveles de base, como así también expansión de los cuerpos lagunares (Mar Chiquita, Lago del Estero, etc.).

Por medio del análisis de datos históricos se verificó que el clima rei- 
nante en el centro-oeste argentino durante el siglo Xvir fue más húmedo respecto al siglo XVIII. Este evento se caracterizó por una mayor estabilidad climática señalada por escasos registros de crecientes extraordinarias y un ínfimo número de sequías (Prieto y Herrera, 1992). Se han detectado, en el centro de la región, numerosas citas de precipitaciones abundantes, destacándose un pico entre 1650-1660 y otro en 1720-1740 (Prieto y Jorba, 1991).

Se produjeron grandes crecidas del Río Dulce que provocaron importantes pérdidas en la ciudad de Santiago del Estero, a causa de las frecuentes inundaciones se decidió el traslado de la Sede del Episcopado a Córdoba en 1690 (Herrera-Dussel, 1991). La región bañada por las aguas del Río Dulce tuvo su máxima expansión económica y política durante los siglos XVI y XVII (Assadurian, 1983).

En 1660, el Río Salado incrementó su caudal y mantuvo su nivel, por causa de esta creciente extraordinaria se decidió el traslado de la Ciudad de Santa Fe a su sitio actual (Prieto y Jorba, 1991).

Fuera del área de estudio también pudo determinarse el mejoramiento de las condiciones climáticas. Al Sureste de la región (E de la Provincia de Buenos Aires) por medio de la investigación de los Acuerdos del Extinguido Cabildo de Buenos Aires, se verificó que durante los siglos XVI y XVII el clima reinante era similar al presente, el relevamiento del registro entre 1589 a 1697 muestra que un $85 \%$ de los años fueron «normales» (Politis, 1984).

Este mejoramiento fue convergente con un retroceso de los glaciares en los Andes Patagónicos, Heusser (1961) determinó un estado recesivo durante la última década del siglo Xvi.

En los Andes Peruanos también fue notado este evento, Cardich (1980) hace referencia a un mejoramiento entre ambos picos mínimos. A nivel global los índices de actividad solar, indican un máximo que abarca los siglos XVI y XVII (Riccardi, 1995).

Segunda Pulsación. Este período se inicia a principios del siglo XVIII y se extiende hasta el inicio del siglo XIX. Se trata del momento máximo de la PEH cuando los glaciares de la Cordillera de los Andes tienen su mayor avance y las llanuras de la región central del país padecen un intervalo de intensas sequías (Politis, 1984; Rabassa et al., 1987; Iriondo, 1994; Iriondo y Kröhling, 1995).

La cartografía jesuítica de la época (Furlong, 1946) muestra importantes cambios en la red de drenaje (reducción de la longitud de los cau- 
ces, cambio de cursos, bifurcaciones, etc.) y disminución o desaparición de lagos y lagunas. Los mapas también hacen referencia de nieve en las sierras de Córdoba (Torres Revello, 1938) y a estepas desérticas en el sector Sur y Sureste de la región (Furlong, 1946).

Los datos históricos revelan un importante déficit de precipitaciones durante el siglo XVIII y comienzos del XIX en toda la región (Prieto y Jorba, 1991) combinada con grandes oscilaciones anuales y marcados ciclos de sequía y humedad (Prieto y Herrera, 1992).

En este período se inicia la decadencia del sector Norte de la región (Provincia de Santiago del Estero), el desmejoramiento climático junto con profundos cambios en la estructuración político-económicas termina con el apogeo vigente durante los dos siglos anteriores (HerreraDussel, 1991).

La máxima serie de sequías se produce a partir de 1770, destacándo la producida en 1786-1787, para el Oeste de la región (Prieto y Herrera, 1992).

$\mathrm{Al}$ este de la provincia de Buenos Aires, fuera del área de estudio, el clima durante el siglo XviII se caracterizó por ser más árido que el presente, las Actas del Extinguido Cabildo de Buenos Aires, permiten establecer un 72,6\% de años secos en el intervalo 1698-1791 (Politis, 1984).

Durante el pulso principal de la $\mathrm{PEH}$ la provincia climática patagónica (árida y fría) avanzó hacia el NE entre 300 a 400 km, aproximadamente hasta el paralelo $34^{\circ}$ (Iriondo y García, 1993; Iriondo, 1994).

La información proveniente de la región andina meridional, señala que los glaciares llegaron a su máxima extensión sincrónicamente con condiciones más secas de las llanuras centrales del país (cuadro II).

En los Andes Centrales también pudo detectarse este evento, los intensos fríos provocaron en la cuenca del Lago Titicaca un descenso de los límites superiores de cultivo, los pobladores abandonaron los pueblos altos y se instalaron en las cercanías del lago (Cardich, 1980).

En la ciudad de Asunción (Paraguay) y NE de Argentina se registraron intensas heladas durante 1786 y 1789, sincrónicamente con grandes crecientes de los ríos principales de la región, que nacen en la Cordillera de los Andes (Herrera-Dussel, 1992).

Esta pulsación fría puede relacionarse con el Mínimo Maunder (mínimo de actividad solar) que abarca el intervalo entre 1650-1770 (Riccardi, 1995). 


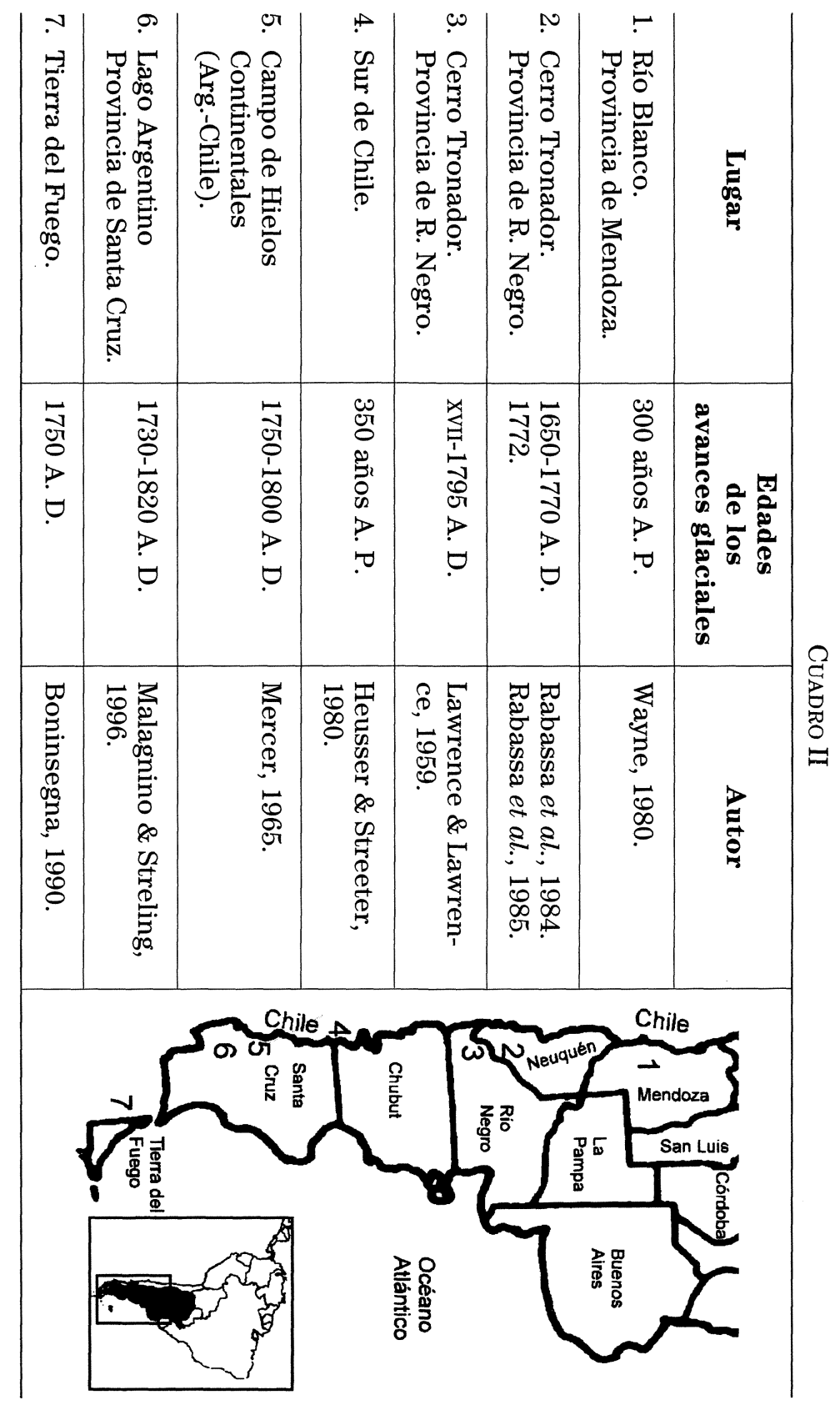

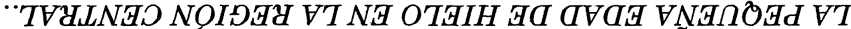


Variaciones del clima actual. Las características climáticas presentes se inician a partir de mediados del siglo pasado. En la región central del país se instalan condiciones más benignas, en correspondencia se intensifica el retroceso de los glaciares andinos (Malagnino y Strelin, 1996) repitiendo las condiciones del Período Intermedio de la PEH.

A partir de mediados del siglo XIX se inicia el registro continuo de datos climáticos para el centro del país. La serie de lluvia anual en la ciudad de Córdoba en el período 1860-1986 muestra una variación de la tendencia. La componente total anual de lluvias permaneció estable desde 1860 hasta 1950, a partir de 1960 comenzó un ciclo progresivamente más lluvioso con una tasa de incremento del orden de los 8,5 mm/año (Lucero, 1994).

Los glaciares patagónicos permanecieron en condiciones estacionarias hasta 1850, prosiguió un retroceso lento desde 1855 hasta 1910, con avances periódicos. Continuó una retracción rápida entre 19101940 con cambios escasos y algunos avances en la década de 1950 (Heusser, 1961).

Estudios detallados efectuados en el Glacial Upsala (Lago ArgentinoSanta Cruz) establecieron una velocidad de retroceso promedio de 60 m/año, a partir del año 1800 (Malagnino y Strelin, 1996).

\section{BIBLIOGRAFÍA}

ASSADURIAN, C. S.: El sistema de la economía colonial. El mercado interior, regiones y espacio económico. México, 1983, Editorial Nueva Imagen, 130 pp.

Boninsegna, J.; KeEgan, G.; Jacoby, R., y Holmes, R.: «Dendrocronological studies in Tierra del Fuego, Argentina», Quater. of South Amer. \& Ant. Pen. (7), 1990, pp. 305-326.

Bonnin, M.; Laguens, A., y Díaz, S.: "Ambiente actual y pasado en la cuenca del Río Copacabana (Dpto. Inschillín, Pcia. de Córdoba, Argentina). Una primera aproximación», Pub. Inst. de Antrop. Fac. de Fil. y Human. Univ. Nac. de Cba. XLV, 1987, pp. 29-66.

DE BliJ, H. J., y Muller, P. O.: Physical geography the global environment, USA, 1993. Wiley \& Sons., $576 \mathrm{pp}$.

DARGAM, M.: «Geochemistry of waters and brines from Salinas Grandes basin, Córdoba, Argentina, 1. Geomorphology and hidrochemical characteristics», Inter. Jour. of Salt Lake Res., 3, 1995, pp. 137-158.

Díaz, S.; Bonnin, M.; LAGUENS, A., y PRIETo, M.: «Estrategias de explotación de los recursos naturales y procesos de cambio de la vegetación en la cuenca del Río Copacabana», Pub. Inst. de Antrop. Fac. de Fil. y Human. Univ. Nac. de Cba., XLV, 1987, pp. 63-133.

CaPitanelli, J. C.: «Geomorfología», Geogr. Fís. de la Prov. de Cba., 1976, Vázquez, J. B. Miatelo, R. A. y Roqué, R. A. (eds.), pp. 213-296.

$$
-266-
$$


CARDICH, A.: «El fenómeno de las fluctuaciones de los límites superiores del cultivo en los Andes: su importancia», Rel. de la Soc. Arg. de Antrop., XIV, n. ${ }^{\circ} 1$ (NS), 1980, 7-31.

Carignano, C.: «El Holoceno en la Provincia de Córdoba», Rev. del Ins. de Geol. y Min. Univ. Nac. de Jujuy, vol. 11, n. ${ }^{\circ} 2,1997$, pp. 1-20.

Fidalgo, F.: «Provincia de Buenos Aires - Continental», Holoceno en la Argentina-Cadinqua, vol. 1, 1991, 23-38.

FidAlgo, F. \& RABASSA, J.: «Los depósitos cuaternarios», Geología y Recurso Naturales de la Provincia de Río Negro. Rel. del IX Congr. Geol. Arg. Buenos Aires, 1984, pp. 301316.

Furlong Cardiff, G. (1937): Cartografía Jesuítica del Río de La Plata, Buenos Aires, 1937. Pub. Inst. de Inv. Hist. LXXI, 125 pp.

GENTILE, R. O.: «Suelo enterrado por depósitos postconquista en la cuenca del A ${ }^{\circ}$ Azul (curso superior), Provincia de Buenos Aires», Simp. Inter. sobre Loess, 1990, pp. 127-130.

Gez, J. W.:» Geografía de la Provincia de San Luis, Bs. As. 1938. Ed. Peuser, 235 pp.

GoNZÁLEZ, M. A.: «Evidencias paleoclimáticas en la Salina del Bebedero», VIII Congr. Geol. Arg. Actas 3, 1981, 411-434.

HERRERA, R., y DuSELL: «Eventos climáticos extremos y ambientes en el Santiago del Estero de la segunda mitad del siglo XVIII», Junta de Andalucía. Proyecto NOA 3, 1992, pp. 7-33.

HEUSSER, C. J.: «Some comparations between climatic changes in North-Westem North America and Patagonia», Annals New York Acad. Sci., 95 (1), 1961, pp. 624-757.

HEUSSER, C. J., y STREETER, K.: «A temperature and precipitation record of the past 16,000 years in southern Chile», Science, 210, 1980, pp. 1345-1347.

IRIONDO, M.: «Geomorfología y Cuaternario de la Provincia de Santa Fe (Argentina)», D'orbignyana, 4, 1987, 1-54.

- : «El Chaco», Holoceno en la Argentina, vol. 1, CADINQUA (Iriondo Ed.), 1992, 5063.

: «Los climas cuaternarios de la región pampena», Com. Mus. Prov. Cs. Naturales «Florentino Ameghino», 4, n. . 2, 1994, 1-48.

_ _ :Climatic changes in the south american plains: a continent - size oscillation», Quaternary International, 1997 (en prensa).

— y GARCÍA, N.: «Climatic varations in the Argentine plains during the last 18,000 years», Palaeogeography, Palaeoclimatology, Palaeoecology, 101, 1993, 209-220.

- y KRöHLING, D.: «El Sistema Eólico Pampeano», Com. Mus. Prov. Cs. Naturales «Forentino Ameghino», V 5, n. ${ }^{\circ} 1,1995$, pp. 1-68.

- y RAMONELL, C.: «San Luis», Holoceno en la Argentina, vol. II, CADINQUA (Iriondo ed.), 1993, pp. 131-162.

KRÖHLING, D.: Geomorfología del tramo inferior del Río Segundo. Inf. final Beca de Iniciación CONICOR, inédito, 1993, 181 pp.

LAGUENS, A.: «Locational structure of archaeological underground storage pits in northwest Córdoba, Argentina», Rev. do Mus. de Arq. e Etnol., S. Paulo, 3, 1993, 17-33.

—_ y BonNin, M.:«Espacio, paisaje y recursos. Estrategias indígenas alternativas y complementarias en la cuenca del Río Copacabana (Dto. Ischilín, Córdoba, Argentina). Sitio el Ranchito. 1000 a. C.-1600 d. C. Pub. Inst. de Antrop. Fac. de Fil. y Human. Univ. Nac. de Cba., XLV, 1987, pp. 159-201.

LATRUBeSSE, E., y RAMONELL: «Formación Algarrobito: Registro de la Pequeña Edad del Hielo en San Luis», 2. ${ }^{a}$ Reunión PICG-281, Publ. Esp., n. ${ }^{\circ}$ 2, 1990, pp. 1-7.

LAWRENCE, D., y LAWRENCE, E. G.: «Recent glacier variations in Southen South America», Technical Report, Off. of Nav. Res. Contract $167 n{ }^{\circ} 641$ (04), Amer. Geograph. So., 1959, pp. 1-39.

Levene, R.: Historia de la Nación Argentina. Buenos Aires, 1938. Acad. Nac. de Historia, $567 \mathrm{pp}$. 
LEVILleR, R.: «Extensión de la Conquista hacia el Sur, II parte», Nueva crónica de la conquista del Tucumán, tomo II, 1927, pp. 47-104.

LutTi, R.; Bertrán, M. A.; Galera, F. M.; Müller, N.; Serzal, S.; Nores N.; Herrera, M. A., y Barrera, J. C.: «Vegetación», en Geogr. Fis. de la Prov. de Cba. Córdoba, 1976, Vázquez, J. B.; Miatelo, R. A., y Roqué, R. A. (Eds.), pp. 297-368.

Malagnino, E. D. y STRELIN, J. (1996): «Oscilacions del englazamiento en el brazo Norte del Lago Argentino y península Herminita desde el Holoceno Tardío hasta la actualidad», XIII Congr. Geol. Arg., Actas IV, 1986, pp. 290-308.

MERCER, J. H.: «Variations of some patagonian glaciers since the late-glacial: II, Am. Jour. of Sc., vol. 269, 1970, pp. 1-25.

PANIGATTI, J.: «Molisoles del Norte de la zona pampeana - génesis y morfología», $I N$ TAEERA, Rafaela. Public. Téc., n. ${ }^{\circ} 13,1981$, pp. 1-22.

PARRAS, P.: Diario y derrotero de sus viajes, Bs. As., 1943. Solar Ed. 251 pp.

Politis, G. (1984): «Climatic variations during historical times in Eastem Buenos Aires Pampas. Argentina», Quater. of South Amer. and Ant. Pen., vol. 2, 1984, pp. 133-161.

PRIETO, M. DEL R. y HeRRERA, R. G. (1991): «Las perturbaciones climáticas de fines del siglo XVII en el área andina», Junta de Andalucía. Proyecto NOA 1, 1991, pp 7-35.

PRIETO, M. DEL R., y JoRBA, R. A.: «Las anomalías climáticas en la Cuenca del Plata y NOA y sus consecuencias socioeconómicas. Siglos XVI-XVII y XVIII», Sep. Leng. Revista Argentina de Geografía, n. ${ }^{\circ}$ 1, 1990, 41-103.

RaBASSA, J.; BRANDANI, A.; Boninsegna, J., y Cobos, D.: «Cronología de la Pequeña Edad del Hielo en los glaciares Río Manso, Castaño Overo y Tronador, Provincia de Río Negro», IX Con. Geol. Arg., Actas III, 1984, 624-639.

Rabassa, J.; Brandani, A.; Salemme, M., y Politis, G.: «La Pequeña Edad del Hielo (siglos XVII a XIX) y su posible influencia en la aridización de áreas marginales de la Pampa Húmeda (Provincia de Buenos Aires)», 1. ${ }^{a}$ Jor. Geol. Bon., Actas, 1985, pp. 560-577.

RABASSA, J.; Heusse, C., y RUTTER, N.: «El tardiglacial y Holoceno de Tierra del Fuego», Holoceno en la Argentina-CADINQUA, vol. 1992, pp. 103-120.

RAMONEll, C.; IrIONDo, M., y KRÖMER, R.: «Guía de Campo n. ${ }^{\circ} 1$ Centro-Este de San Luis», 5. ${ }^{\circ}$ Reunión de Campo CADINQUA - Univ. Nac. de San Luis, 1992, pp. 1-37.

RAMONEll, C.; Tulio, J.; CAlmels, A., y CARBAllo, O.: «Unidades litoestratigráficas del Cuaternario superior en el área de Santa Rosa, Prov. de La Pampa», Actas del Cur. de Posgrado Introduc. al Est. del Cuaternario», 1993, pp. 233-242.

RiCCARDI, C.: «Paleoclima», Cambio Global. Publ. Esp. Acac. Nac. de Geogr., n. ${ }^{\circ} 10$, 1995, pp. 91-126.

TonnI, E., y FidAlgo, F.: «Consideraciones sobre los cambios climáticos durante el Pleistoceno Tardío-Reciente en la provincia de Buenos Aires. Aspectos ecológicos y zoogeográficos relacionados», Ameghiniana, tomo XV, n. ${ }^{\circ}$ 1-2, 1978, pp. 235-252.

ToRREs Revello, G.: «Mapas y planos referentes al Virreynato del Río de La Plata (Archivo de Simancas)», Bs. As. 1938. Ed. Peuser, $251 \mathrm{pp}$.

VÉscovo, A. M.: «La cuenca del Desaguadero», Atlas Total de la República Argentina, vol. 22,1981, pp. 344-348

WAYNE, R.: «La evolución de glaciares de escombros y morenas en la cuenca del Río Blanco, Mendoza», VII Cong. Geol. Arg., Actas IV, 1981, pp. 153-166.

Resumen: La región está ubicada al Este de la Cordillera de los Andes y al Oeste del Río Paraná, entre los paralelos $28^{\circ} \mathrm{S} \mathrm{y} 36^{\circ}$ S. Durante «La Pequeña Edad del Hielo» se identificaron dos pulsaciones frías separadas por un período intermedio. La primera se extendió desde comienzos del siglo xv hasta finales del siglo xvi y la segunda abarcó la etapa comprendida entre principios del siglo xviII y primeras décadas del siglo XIX. 
Finalmente, comenzó una progresiva suavización de las condiciones climáticas a partir de la segunda mitad del siglo XIX.

Se determinó que en el sector occidental (dominio andino) reinaban condiciones de clima frío y húmedo, con avance de los glaciares en cordillera y expansión de los sistemas fluviales-lagunares. El sector oriental (dominio pampeano) presentaba un clima árido-semiárido, caracterizado por la retracción generalizada de los sistemas fluviales-lagunares, alta movilidad en la posición de los cursos de los ríos, generación de nuevos sistemas de abanicos aluviales e intensificación de procesos eólicos.

Palabras claves: Cambio climático. Pequeña Edad del Hielo. Región central de la República Argentina. 